\title{
OCIO EN EL MODELO LABORAL OPERARIO COLOMBIANO
}

\author{
LEISURE IN COLOMBIAN OPERATOR WORK MODEL
}

Mabir Lubieth Reyes Rivera ${ }^{1}$

\section{Resumen}

Este artículo presenta un recorrido histórico que comienza con el surgimiento de la época reconocida como Revolución Industrial y su influencia en las luchas obreras que a través del tiempo marcaron, de alguna manera, la percepción del trabajo tanto por parte de los trabajadores como de los mismos dueños de las fábricas, y luego esta en el contexto de la vida de los trabajadores colombianos a comienzos del siglo xx. Culminando este recorrido se busca encontrar el vínculo del trabajo y del ocio con la población trabajadora colombiana que se ve envuelta en una historia de resistencia sindical y transformación educativa que, sin duda, influye en el reconocimiento que esta población tiene en la actualidad de estos dos actos, llegando a una serie de confrontaciones finales que resultan en interrogantes e invitan a la reflexión.

Palabras claves: ocio, trabajo, trabajador operario, educación.

\section{Abstract}

This article presents a historical journey that begins with the emergence of the era recognized as an industrial revolution and its influence on the workers' struggles that over time somehow marked the perception of work by both workers and owners themselves factories and then this in the context of the lives of Colombian workers in the early twentieth century. With this journey culminated, it seeks to find the link between work and leisure with the working population Colombian who becomes embroiled in a story of labor union resistance and educational transformation that undoubtedly it influence in the recognition that this population now has these two acts coming to a series of confrontations that result in final questions and thought-provoking.

Keywords: leisure, work, worker operator, education.

Fecha de recepción: 15 de mayo de 2015

Fecha de aprobación: 1 de octubre de 2015

Para citar este artículo:

Reyes, M.L. (2015). Ocio en el modelo laboral operario colombiano. Lúdica Pedagógica, (22), 101-110. 


\section{A MODO DE INTRODUCCIÓN}

Es posible discutir acerca de que el ocio ha sido una palabra fuertemente debatida en cuanto a su influencia en determinadas culturas, sociedades, gremios, etc. Por otro lado, su relación con el trabajo - reconocido este como un acto de esfuerzo físico o mental que realiza una persona a cambio de un salario o remuneración económica一, en la época conocida como Revolución Industrial (de mediados del siglo XVIII a mediados del siglo XIX), es un momento histórico que da inicio a un comportamiento de resistencia con un rostro de clase social obrera que comenzaba a sentir la necesidad de exigir mejores condiciones laborales para su bienestar propio. Las exigencias en general incluían aumentos salariales, infraestructuras de trabajo dignas y disminución del horario laboral. Esta última petición es la que trae consigo la conciencia del tiempo libre que paralelamente se relaciona con el tiempo del que podría disponer el trabajador de manera libre, fuera de la jornada laboral y diferente al tiempo utilizado para dormir, y es allí donde poco a poco se va introduciendo el campo teórico que envuelve al ocio.

Aunque las primeras vivencias de la clase obrera tuvieron lugar en Europa y Estados Unidos, es de interés primario de este escrito reconocer dicho momento histórico en el contexto colombiano, que también cobijó al mencionado gremio trabajador a comienzos del siglo xx, que es cuando en Colombia se vive la Revolución Industrial. En la actualidad prevalece el modelo laboral de producción masiva y en cadena, pero también persiste el desconocimiento de aquel tiempo de ocio por el que pelearon ancestros obreros. Partiendo de estos hechos, se desea propiciar entonces preguntas que problematicen la influencia de un sistema educativo en la forma en que los trabajadores perciben el ocio, el trabajo y su relación: ¿Se educa para el trabajo? ¿Está diseñado el sistema educativo nacional pensando en la felicidad de los educandos? ¿Está el ocio pensado dentro de la educación?

\section{REVOLUCIÓN INDUSTRIAL}

La llegada de la Revolución Industrial en el siglo XviII generó un impacto en relación con las modalidades de trabajo y la forma en que una persona consume un producto determinado. Esta etapa llegaba con intenciones de impacto y de transformaciones gigantes que fueron evidenciadas durante un largo siglo, dejando como resul- tado todo lo que conocemos como producción masiva y en cadena, y lo que implica esto para los distintos actores como trabajadores, empleadores e, incluso, los mismos consumidores.

La Revolución Industrial impactó en primera medida la forma de elaboración de productos para el consumo, que para ese entonces era más artesanal. Elizalde y Gomes (2010) exponen un análisis, hecho por Marx, que explica la diferencia entre el modelo de trabajo que existía antes de esta revolución y el que llega con esta, nombrándolos él mismo como trabajo concreto y trabajo abstracto:

[...] el trabajo concreto representa una necesidad de realización humana; en cambio, el trabajo abstracto es apenas un medio de subsistencia, garantizado bajo una forma de pago de un salario que genera, potencialmente, un proceso de alienación. Este proceso, también denominado de "extrañamiento", no se vuelve efectivo solo en el resultado, sino que también va a abarcar al propio acto de producción. (Elizalde y Gomes, 2010, p. 251).

El trabajo es y ha sido un acto reconocido por la humanidad, que se realiza con el fin de recibir una remuneración a cambio, y aunque durante el tiempo se han elaborado un sinnúmero de teorías y conceptos a partir de este, la base será la sencilla definición del Diccionario de la Real Academia Española: “Trabajo: ocupación retribuida”, que significa la recepción de dinero por un trabajo físico o intelectual que se realiza.

Así, existen variadísimas categorías del trabajo, algo así como tipos o clases que se diferencian por sueldo, rango, esfuerzo mental o físico, etc. Cada cual tiene características distintas, y aquí se notará que la orientación va hacia un trabajador que da continuidad a una parte de la historia que ha marcado el sistema económico, laboral y de producción durante años, de todos aquellos países que fueron tocados por la Revolución Industrial; un trabajador que continúa formando parte de la producción masiva, del trabajo fabril, repetitivo y considerablemente mal pagado. Este trabajador se llama operario, producto de un cambio de nombre en la época de la Revolución Industrial; desde mediados del siglo XVIII hasta mediados del siglo XIX, era reconocido como clase social proletaria o trabajadora y su composición etimológica ocasionó que fuera llamado operario.

OBRAR, h. 1140. Del lat. Operari 'trabajar', derivado de Obrada, 1220-50. Obraje, 1528, del cat. obratge; obrajero. Reobrar 'reaccionar', h. 1900. Obra. h. 
1250; antes huebra, h. 1140 (especialmente en la ac. 'cantidad de trabajo que se hace en un día', y hoy todavía 'medida de lo que puede labrarse con esta cantidad'), lat. Opera 'trabajo, labor'; ópera, 1737. del it. ópera íd., propte. 'obra'; opereta. Obrero, 1056, lat. Operarius íd. (operario. princ. S. XVII, cultismo) obrería; obrerismo. obrerista. Cultismos: Operar, 1737; operación. 1433; operador; operante; operativo. (Corominas, 1987, pp. 419-420).

Y aunque autores como Archila (2010) incluye dentro del grupo de obreros al sector manufacturero ${ }^{2}$, a la fecha dentro de nuestro código lingüístico en este campo, se reconoce al tipo de trabajador del que hablaremos en este escrito como operario.

El ahondamiento de la industria era a pasos agigantados, afectando de manera evidente a los artesanos y campesinos que veían perder su futuro en los campos o en sus talleres, pues la rentabilidad económica parecía verse prometida a las fábricas que comenzaron a ser los hogares de familias enteras, porque el trabajo en estos sitios no era solo para hombres, ya que las mujeres y los niños resultaban también útiles para las producciones: "El tiempo diario de trabajo, iría en aumento para hombres, mujeres y niños hasta llegar, con suma rapidez, a extremos agotadores" (Miranda, 2006, p. 310).

Las luchas de la clase obrera europea contra los burgueses o capitalistas se basaban en disminución del horario laboral y aumento salarial, según el sociólogo marxista italiano Gianni Toti (citado por Miranda, 2006), y a partir de allí la referencia del tiempo libre comenzó a notarse igual que la identificación de la necesidad del descanso y del ocio. Miranda (2006) rescata los inicios de organizaciones sindicales en Estados Unidos a partir de 1791 en Filadelfia con la primera acción a favor del tiempo libre, y también resalta la dedicación de estos trabajadores a la hora de luchar por la obtención de la disminución de la jornada laboral, haciendo uso del poco tiempo que les quedaba después de las largas jornadas, para estudiar la normatividad que luego querrían transformar. Ahora no solo lucharían, a mediados del siglo XIX, por un simple descanso sino por "la reivindicación de un verdadero tiempo libre [...], libre también de la necesidad de

2 Para profundizar la clasificación del grupo de la clase obrera que hace este autor, revisar páginas 18 y 19. descansar, con derecho a reservar cada día un poco de tiempo para su propia educación y para mejorarse a sí mismos" (Miranda, 2006, p. 313).

\section{ALGO DE LA HISTORIA OBRERA Y SUS LUCHAS EN COLOMBIA}

En su mayoría, esta parte del escrito está basado en dos autores que han realizado un excelente trabajo con el estudio de la historia obrera y sindical de Colombia: Archila (2010) y Caicedo (1974). Sus recopilaciones describen, primero, la historia de estos trabajadores con la llegada de la industria en un país que acababa de pasar por un proceso de independencia luego de una colonización de casi medio milenio, en el caso de la investigación de Archila, y segundo, las conformaciones sindicales en el país desde una postura crítica un poco más fuerte, en el caso de Caicedo.

Para cuando la Revolución Industrial en Europa era ya una historia de casi dos siglos, en Colombia - primera década del siglo $\mathrm{xx}$ - apenas comenzaba a abrirse campo con un hambre feroz que alcanzó a sembrarse en los campesinos y artesanos que, casi en su totalidad, terminaron convirtiéndose luego en la clase obrera luchadora de distintas formas.

La época, notoria a comienzos del siglo xx, "se la conoce como 'los años del ruido'. [...] sirenas de las fábricas, bocinas de los carros, pitos de los ferrocarriles, música de la vitrola y, allá en el fondo, el creciente clamor de la protesta social" (Archila, 2010, p. 85).

Archila propone que el grupo trabajador colombiano sea referenciado como una clase, y para este caso, clase obrera - tal como se identificó en Europa-, que existe y que ha existido en Colombia aun con varias y diferentes percepciones de esta definición. Archila (2010) describe como obreros

[...] a todos aquellos trabajadores, del campo o la ciudad, que laboran directamente los medios de producción y que dependen básicamente de un salario para reproducirse. En esta definición caben desde los asalariados de los talleres artesanales -históricamente los primeros en ser designados como "obreros"-, hasta los jornaleros agrícolas, pasando por los trabajadores manufactureros, los de los medios de transporte y de la minería (p. 18). 


\section{Y clase como}

[...] algo más que la simple sumatoria de esos obreros: la clase es un resultado histórico al que llegan los trabajadores asalariados cuando las condiciones económicas, políticas y el proceso cultural de identificación lo permiten. [...] Pertenecer a la clase es identificarse como un nuevo conglomerado social que da sentido a quienes comparten unas condiciones de explotación similares (p. 19).

También este autor asegura que es importante entender que no es fácil hablar de clase burguesa en los países latinoamericanos para finales del siglo XIX e incluso comienzos del xx: "Al contrario del caso europeo, en América Latina los sectores que podrían ser catalogados como 'burgueses' no lograron sino una identidad alrededor del proyecto exportador. Pero allí también estaban articulados otros grupos como los terratenientes, o los grandes mineros" (Archila, 2010, p. 19), y por esto prefiere referirse a estos como élite y no como burgueses ${ }^{3}$.

Con la industria, la población campesina fue la que sufrió más la necesidad de emigrar a las ciudades en busca de trabajo, obligando a estas a estructurarse físicamente para soportar la cantidad de población que ahora se quedaba en busca de oportunidades laborales.

Experimentando entonces situaciones de salarios mínimos, jornadas laborales extendidas y condiciones paupérrimas en sus lugares de vivienda, el campesinado terminó convirtiéndose en "el grueso de la clase obrera colombiana" (p. 86) y más tarde haría parte de las futuras organizaciones y sindicatos que lucharían por esta clase, junto con el gremio artesano que, a comienzos del siglo $\mathrm{xx}$, decidió unirse a la "naciente clase obrera" (p. 88).

En este aspecto, Caicedo (1974) habla de tres etapas relacionadas con la periodización sindical en el país, siendo la primera Formación (1900-1929) en donde menciona a la primera organización gremial que consigue personería jurídica, el "Sindicato de Tipógrafos" de Bogotá, en 1906, gremio que formaba parte de los trabajadores artesanos (p. 49), y aunque para mediados del siglo XIX ya existían agrupaciones conformadas por estos mismos, dice Caicedo (1974), "no podemos considerarlas como antecedentes directos desde cuya evolución surgieran los actuales sindicatos" (p. 49),

3 Archila explica el origen o significado de las palabras obrero, clase y élite, y por qué en nuestro país es difícil hablar de burguesía. Más claramente léase la introducción de ese gran libro. notándose la primera acción proletaria de la que se tenga noticia alguna en 1910, por parte de "braceros portuarios, obreros de la construcción, transportadores y ferroviarios, desde Calamar hasta Barranquilla". Sin embargo, no se aclara que este sea organizado por el sindicato en mención. Luego, en 1918 estallan masivamente huelgas en los puertos de Barranquilla y Cartagena, siendo apoyados posteriormente por trabajadores en Santa Marta y los obreros de las zonas bananeras ante la United Fruit Company, evento que culminó en masacre años después (p. 51).

En la segunda etapa, Ascenso y desviación (1930-1945), incluye la primera acción que condujo a resultados relacionados con el descanso o disminución laboral, que fue durante el gobierno liberal de Olaya Herrera (1930-1934), donde los obreros consiguieron vacaciones remuneradas y jornada laboral de ocho horas (Caicedo, 1974, p. 64); y la tercera etapa Paralelismo y violencia (1946-1957) básicamente relaciona la caída de la Confederación de Trabajadores de Colombia (СтC) - sindicato colombiano formado entre los años 1929 y 1933 - y la victoria del Partido Conservador a la Presidencia colombiana.

Caicedo hace un barrido histórico sindical que da cuenta de las glorias - significativas pero no en todos los casos- y las fallas huelguísticas que decoran la situación obrera e incluso laboral en la actualidad. La población obrera en Colombia comenzaba a resistirse a la proletarización porque "querían ser dueños de su trabajo" (Archila, 2006, p. 103) así como por alcances económicos que la proletarización no cubría.

La prensa desempeñó un papel importante en esta época. Los voceros de los nacientes movimientos obreros, por medio de esta, divulgaron sus preceptos políticos, pretendiendo mostrar a los lectores el contexto político de ese momento para, quizás, difundir el inconformismo; y aunque los niveles de analfabetismo en esta población eran considerables —desde el año 1900 hasta 1950 osciló entre el 40 \% y el 60 \% (Banco de la República, 2006) - durante varias décadas del siglo xx en diversos rincones del país, se imprimían centenares de números de periódicos como El Yunque (Bogotá, 1906), El Proteccionista (Bogotá, 1910), El Símbolo (Cartagena, 1910), Un Obrero Moderno (Bucaramanga, 1913), La Unión Obrera (Bucaramanga, 1919) y El Socialista (Bogotá, 
1928) ${ }^{4}$. Es evidente el interés de los escritores de estos tabloides, de dar a conocer al pueblo las eventualidades políticas y gubernamentales que explotaban a su gente, mostrándoles por este medio las alternativas de cambio que surgían por ese entonces: el socialismo y el comunismo. Así, los periódicos de esta categoría rendían homenaje a los líderes caídos y denunciaban las arbitrariedades del Estado pretendiendo exaltar la ira de sus lectores.

Dentro del grupo de características que hasta el momento se han tratado, es necesario relacionar la influencia de la religiosidad en las luchas obreras colombianas, pues los autores hablan en varias ocasiones de la orientación religiosa de los dirigentes socialistas cuando se referían a la lucha: "Lo que reivindicaban los artesanos y los primeros núcleos obreros no era tanto la dimensión espiritual del catolicismo sino la proyección social del cristianismo en general" (Archila, 2006, p. 89). Pero paralelamente también el furor occidental del socialismo y el comunismo alejaban al clero y a las mismas creencias cristianas del pueblo obrero, pues el primero seguía siendo razón de fuertes críticas que se mostraban así en algunas páginas de este tipo de prensa: “Quién, no más que el clero, es responsable de las guerras civiles en Colombia?" (Capella, 1910, p. 1) $)^{5}$ y el segundo iría perdiendo su fuerza o no lograría mantenerse en las creencias de la totalidad de los luchadores obreros. Pero este mencionado clero no podía permitirse ser alejado del pueblo que creía en su palabra, y así comenzó a aliarse, a su manera, a las luchas obreras creando grupos como la Juventud Obrera Católica (JOC), que tenía apoyo internacional, y más tarde, cuando la hegemonía conservadora ataca de nuevo al país y con la desaparición de la Confederación de Trabajadores Colombianos (CTC), comienza a organizar, con el apoyo de los empresarios, "a los obreros, inculcándoles un espíritu paternalista cristiano castrado de toda combatividad" (Caicedo, 1976, pp. 81-82).

4 Para profundizar la lectura de los artículos impresos en estos periódicos, véase: Biblioteca Digital Nacional de Colombia: http://www.bibliotecanacional.gov.co/content/imprenta-prensa-obrera-y-lecturas-populares-prensa-obrera\#fundamentos

5 O también se puede leer el número 12 del periódico El Obrero Moderno, de Bucaramanga, 7 de junio de 1913, que trae consigo fuertes acusaciones al clero. Véase: http://www.bibliotecanacional.gov.co/recursos_user/expv/pobrera/elobreromoderno_12_bucaramanga_1913.pdf
El recorrido histórico de las luchas obreras colombianas acerca al lector a dos factores relevantes para comprender la vivencia del ocio en el trabajador operario actual: el analfabetismo, que nos conducirá a una realidad educativa actual, y la influencia de la religión en las luchas. En el siguiente apartado se mostrarán algunas concepciones de ocio desde distintas miradas (positivas y negativas) para poder articularlo con estos factores y la actualidad del trabajador operario en Colombia.

\section{OCIO Y TRABAJO EN COLOMBIA}

El ocio, sumergido en infinidad de miradas, concepciones y orientaciones desde hace muchos años, es en efecto una palabra sujeta a múltiples discusiones desde épocas muy antiguas.

Iniciemos entonces con la etimología de la palabra ocio. Según Hernández (2012) "el ocio en Roma surge del latín otium, "descanso", que implica la liberación de los negocios (...). La negación del otium, es el negotium, es decir, trabajo al que se dedicaban comerciantes y mercaderes" (p. 88), reconocido en Roma más como "eminentemente popular de fiestas y espectáculos que será usado también como arma de propaganda y dominio" (p. 88), y en la Grecia Antigua "se expresaba con una polisémica palabra, scholé, que ha derivado nada menos que en nuestra palabra 'escuela'" (p. 77) e indica que para esta Grecia "representaba ante todo un estado de liberación de la necesidad de trabajar (ascholia), que se convierte en primordial para la búsqueda de la sabiduría y la práctica del mejor modo de vida" (p. 78), recalcando que para esta sociedad el trabajo era desprestigiado.

A través del tiempo, esta palabra ha sido víctima de un sinfín de acusaciones que la condenan como inmoral, pues perder el tiempo, no hacer nada y ser vago han sido sinónimos de ocio, juzgados moralmente ${ }^{6}$. De hecho Bertrand Russell (1932) comienza su Elogio de la ociosidad con un acercamiento a lo que hoy en día sigue enseñándose: “Como casi toda mi generación, fui edu-

6 Algunas frases existentes, a través de la historia, de personajes reconocidos muestran la promoción del no ocio, como: "El ocio corrompe el cuerpo humano igual que las aguas quietas", recita el poeta latino Ovidio (43 a. de C.); o "La ociosidad camina con tanta lentitud, que todos los vicios la alcanzan", de Benjamin Franklin; o "Una vida ociosa es una muerte anticipada", de Goethe; o "El ocio es la pérdida del salario", de Francisco de Quevedo, que de alguna manera se relaciona con el tema en mención. 
cado en el espíritu del refrán 'La ociosidad es la madre de todos los vicios'. Niño profundamente virtuoso, creí todo cuanto me dijeron, y adquirí una conciencia que me ha hecho trabajar intensamente hasta el momento actual" (s.p.).

El ocio pasó de ser un símbolo de la contemplación, de "mirar el mundo y lo que nos rodea y disfrutar de su belleza sin pretender imponerle nada" (Rul-lán, 1997, p. 174) — que era como se veía en la Grecia clásica一, a un acto por debajo del trabajo con la llegada del cristianismo, que:

[...] supuso una revolución en los conceptos de contemplación y trabajo, dando un paso enorme a la valorización de la acción (del negocio) — que es considerado como la negación del ocio- en detrimento, a largo plazo, de la contemplación (del ocio). (Rul-lán, 1997, p. 177).

Así como en el Renacimiento, donde "la grandeza del hombre, está en su capacidad para descubrir las causas de lo que ve y su habilidad para someterlo. No se contempla la naturaleza, se la mira y se la examina para poderla dominar con el trabajo" (Rul-lán, 1997, p. 180).

Pero, así mismo, como el ocio ha sido víctima de acusaciones morales durante años, también ha sido acogido por estudiosos que lo conciben como una posibilidad distinta para aligerar el espíritu y la mente del peso del trabajo, las obligaciones y la rutina. Por ejemplo, Joffre Dumazedier indica que el ocio es "un conjunto de ocupaciones a las que puede entregarse a su antojo, sea para descansar, para divertirse, desarrollar su información o su formación desinteresada, su participación social, voluntaria tras haberse liberado de sus obligaciones profesionales, familiares y sociales" (citado por Miranda, 2006, p. 303). Miranda (2006) también piensa el ocio como

[...] un vehículo indispensable para el descanso, sin el ocio no habría recuperación de la fatiga física o nerviosa, de aquí que el descanso significa reposo y liberación: un reposo reparador por la acumulación de las tensiones de una jornada de trabajo. [...] Ocio y diversión buscan placer y bienestar, encontrarse a gusto, vivir de acuerdo consigo. El desarrollo actual del ocio entraña la reaparición de esta moral del placer. Placer rechazado por varios siglos por la moral del trabajo y los valores sociales (p. 304).
Ahora, los escritores brasileños Elizalde y Gomes (2010) analizan el ocio como aquello que el poder siempre ha querido esconder para evitar que el ser humano conozca sus beneficios liberadores:

El ocio puede generar una experiencia de apertura marcada por una actitud que rompa y transgreda con lo permitido y lícito, mostrándose muchas veces al borde de lo socialmente adecuado y aceptado. Justamente a esto se debe uno de los grandes temores, así como peligros que representa el ocio para el mantenimiento del statu quo. De aquí surge, en parte, el intento de acallar y prohibir la disruptividad, contracorriente, alteridad e innovación subversiva, y todo aquello que puede expresar un ocio problematizador, caótico, contrahegemónico y transformacional. Con esto, agregamos que el ocio, a su vez, puede permitir el desarrollo de una nueva identidad y de un sentido de pertenencia más abarcador (p. 11).

Reafirmando esta propuesta, Tabares (2005) hace una relación argumentada del desarrollo humano y el desarrollo económico con el ocio; él le adjudica a las sociedades desarrolladas el seguro que brindan para la aparición del ocio y la recreación "entendida en primera instancia como tiempo libre y acceso a bienes y servicios" (p. 102), y a las subdesarrolladas, aquellos países que no permiten estas apariciones por no considerarlas importantes, es decir, "lugares poco propicios para la aparición de estas prácticas como fenómenos importantes" (p. 102).

Además, Cuenca (citado por Otero, 2009) afirma: “[...] el ocio hay que entenderlo como una experiencia integral de la persona y un derecho humano fundamental. Una experiencia humana [...] centrada en actuaciones queridas, autotélicas (con un fin en sí mismas) y personales" (p. 9).

Tabares (2010) también establece una relación respecto a por qué no es posible comparar la historia del ocio en otros contextos distintos al latinoamericano ${ }^{7}$. Araya (citado por Tabares, 2010) indica que en la etapa de conquista la población indígena se representaba en población libre, lo que significaba "una amenaza para las capas dominantes, quienes como estrategia,

7 Para profundizar más el tema de las modernidades, véase: Tabares, 2010. 
convirtieron a los nuevos libres en plebe, mediante la actualización y relacionamiento de esta población con el antiguo concepto de ociosidad" (p. 7), así, Araya explica:

En primer lugar, la ociosidad era un indicador de la población que tenía la obligación de trabajar. En un primer momento los indios fueron calificados de naturaleza ociosa. En el siglo XVIII, todos los hombres libres - mestizos en un sentido ampliotambién la poseían. El discurso sobre la ociosidad, por tanto, era una teoría antropológica ya que, si era catalogado de ocioso, por naturaleza se era capaz de cualquier vicio, pecado, desorden o delito. La plebe era moralmente inferior. Esta inferioridad legitimó las medidas de orden y disciplinamiento sobre ella, las que se asumieron como objetivos de un buen gobierno. La corrección y el castigo pasaron a ser los principales objetivos de esta nueva tarea civilizadora. (Tabares, 2010, p. 7).

Ahora, la normatividad del trabajo colombiano permite un día de descanso obligatorio, léase bien, "obligatorio, que podrá coincidir con el domingo", según el literal d. del artículo 161 del Código Sustantivo del Trabajo; este no corresponde al tiempo de ocio del que se ha discutido anteriormente, por la caracterización de obligado. Por otro lado, los actos que pueden realizarse de manera libre y espontánea, con el fin de liberarse por unos minutos de los gajes del trabajo, no corresponden a grandes inversiones de tiempo ni dinero, tanto para el empleador como para el empleado; sin embargo, para el trabajador operario no es tan fácil tomarse este tiempo mientras sea el único de la cadena de trabajo que lo hace, pues la detención de un proceso podría afectar claramente la continuidad del que le sigue, hecho por otro trabajador, por lo que el descanso debe ser en el mismo momento para todos los que formen parte de esta cadena de producción.

¿Por qué la modalidad de trabajo de producción masiva y en cadena es parte importante de la vida de un porcentaje muy alto de los trabajadores de Colombia? ${ }^{8}$. ¿Pesa la influencia de una educación traída del exterior, en el futuro laboral de estos trabajadores que no conciben un tiempo de ocio?

8 EI DANE (2012) muestra una cifra del 30,3\% de trabajadores operarios no agrícolas sin ningún título alcanzado para el año 2012.

\section{EDUCACIÓN EN COLOMBIA Y SU INFLUENCIA EN LA CONCEPCIÓN DEL TRABAJO Y EL OCIO}

El camino de la educación se ha trazado en cada rincón del planeta a su forma, a su estilo, según el contexto, las costumbres o según el interés de quien la tuviera en sus manos en ese momento. En la antigua Grecia se conservó una imagen de educación que saltaba la obligatoriedad y en donde la motivación de los educandos era la satisfacción plena de poder contemplar y comprender lo que veía. No había horarios, no había un escenario estrictamente elaborado para dar clases, no existían las asignaturas; cada quien encontraba su lugar de interés así como el tema para la discusión junto con otros estudiantes ${ }^{9}$.

Taylor (2010), en su recopilación, resalta que los profesionales eran técnicos, y que a su cargo nunca estuvieron las grandes decisiones, pues "la opinión dominante sostenía que los técnicos habían esclavizado sus mentes" (s.p.); así, la escuela para ellos era un espacio abierto de discusión y buena amistad sin exámenes, porque "los exámenes que importaban llegaban en la vida" (Taylor, 2010, s.p.), y con espacios de libre elección para aquellos libres que quisieran asistir -habrá que recordar de esta época la existencia de la esclavitud aceptada por la mencionada población que gozaba de dicha educación por ser libres-. Ellos ni siquiera percibían la obligatoriedad de la instrucción, pues esto sería únicamente para los esclavos. En fin, el autor se remonta a la única intención de los atenienses en cuanto a la educación: "No había escuelas en la antigua Grecia. Para los griegos, el estudio era su única recompensa. Pocos se preocupaban de ir más allá de eso" (Taylor, 2010, s.p.).

En Colombia, y para la llegada de la Revolución Industrial a comienzos del siglo $\mathrm{xx}$, la mayoría de trabajadores industriales tenían poco acceso a la escuela, y aunque para los años 1940 en su mayoría sabían leer y escribir, para los años 1920 existía un porcentaje altísimo de analfabetismo ${ }^{10}$. La calificación de la mano de obra era derivada del aprendizaje del oficio en cuestión, más que conocimientos básicos de la escuela, por lo que existían maestros que enseñaban a los aprendices los conocimientos básicos del oficio aunque algunas industrias optaban por acudir a extranjeros cuando requerían

9 Estos abordajes se tomaron de alguna compilación del libro de Taylor, que más adelante se cita con precisión.

10 Archila (2009) menciona entrevistas y estadísticas que cotejan esta información (véase capítulo 2, "La primeras generaciones obreras"). 
mano de obra calificada para ciertos cargos (Archila, 2010). Allí, habiendo hecho los artesanos varios intentos de exigencia al Estado por educación técnica, a finales del siglo XIX, se tomó el modelo del Senai brasileño para conformar en 1956 el Sena (Servicio Nacional de Aprendizaje) (p. 101), institución de formación para el trabajo. Esta conformación revela un interés por la educación para el trabajo, tanto por parte de los empresarios como, al parecer, por parte de los trabajadores. ¿De qué manera puede transformarse un sistema laboral como el mencionado, cuando los mismos trabajadores asumen este modelo como algo natural y necesario?

No se puede pasar de largo la mirada al tema del modelo de educación que permite este tipo de pensamiento opositor al tiempo de ocio, favoreciendo el campo del trabajo y al dinero, porque se considera que es precisamente acá donde la educación para el ocio toma sentido. Es necesario entonces mencionar algunos apartados de artículos de la Ley 115 del 28 de febrero de 1994, que no deja de lado la intención de formar para el trabajo, siendo esta ley promotora, en voz alta, de la educación técnica y tecnológica, hecha especialmente para la formación del futuro trabajador:

La educación media técnica prepara a los estudiantes para el desempeño laboral en uno de los sectores de producción y de los servicios, y para la continuidad en la educación superior. La educación media técnica está dirigida a la formación calificada en especialidades tales como: agropecuaria, comercio, finanzas, administración, ecología, medio ambiente, industria, informática, minería, salud, recreación, turismo, deporte y las demás que requiera el sector productivo y de servicios.

Artículos como el 5 (numeral 11), el 13 (objetivo g), el 20 (objetivo a), el 27 y el 33 (objetivos a y b), reflejan la intención de una educación básica primaria, básica secundaria y media, y una educación técnica, para la formación del trabajo como objetivo principal y necesario para el desarrollo individual y social.

Este modelo educativo se establece más formalmente en Colombia a partir de los años 1990 en la administración de Cesar Gaviria, con la apertura económica, que da comienzo a un proceso de globalización y no deja por fuera a la educación, asegura Martisela Bermúdez Asprilla (2011). También explica:
Por ello, se inicia en las instituciones técnicas, especialmente en el Sena, un nuevo proceso de desarrollo curricular, basado en competencias que poco a poco ha ido llegando a las demás instituciones educativas de orden superior o de educación básica. (s.p.)

Colombia se ha sujetado a un sistema de educación que nació en Francia: la educación prusiana. Modelo surgido a comienzos del siglo XIX de la necesidad de disciplinar y enseñar a los educandos para la guerra. Una de sus más notorias características era la obligatoriedad, que ya de entrada se contradice con el modelo de educación de la Grecia antigua. Posteriormente, y con la llegada acelerada de la industria, la guerra pasó a un segundo plano, y su lugar lo ocupa el trabajo. Y así, Colombia también adquiere esa necesidad de educar a los futuros trabajadores competentes, disciplinados, hambrientos de salarios y con la imagen de un país capitalista y consumidor.

¿Se podría entonces hablar de educación para el ocio? Luego de haber mencionado los inmensos debates alrededor del ocio y sus atributos como posible transformador social para el desarrollo humano, definitivamente debe formar parte de la cultura del hombre pensarse en el espacio de tiempo dedicado a la introspección, a la meditación, al yo mismo, a la reflexión.

La escuela ha dejado de lado la búsqueda de la felicidad pensada de cada individuo, y ha decidido homogenizarla incrustando en la mente de sus educandos una idea de felicidad a partir del éxito, y ese éxito, en nuestro contexto, significa tener más que otros, resultado que solo se conseguirá si se es buen trabajador para lo que puede servir el modelo de educación actual.

\section{CONFRONTACIONES}

\section{CON LA REALIDAD ACTUAL}

Ahora es importante comenzar a explorar los interrogantes que surgen de lo que hasta aquí se ha escudriñado; por ejemplo: ¿Las luchas obreras verdaderamente consiguieron el tiempo que deseaban y que garantizaba un bienestar mental y físico, o simplemente se acogieron a un tiempo libre que les brindaba una sociedad capitalista y consumista?

Gawriszewski (2010) muestra importantes evidencias relacionadas con los resultados de estas luchas obreras y lo que realmente fue y ha sido ganancia para los que, 
en ese momento, eran llamados burgueses. Menciona a la industria del entretenimiento como resultado del "aumento del tiempo libre de los trabajadores" (s.p.), generado por las gigantescas luchas obreras:

Henry Ford encontró una salida: los trabajadores deberían constituirse en consumidores, y por lo tanto sus salarios fueron aumentados sustancialmente, lo cual tuvieron que hacer todos los empresarios. Con el aumento de los salarios, estos nuevos consumidores necesitaban tiempo libre para hacer compras. Entonces, la jornada laboral se redujo para servir a los intereses del capitalismo. (Gawriszewski, 2010, s.p.).

Se ha confundido la orientación del ocio intrínseco, espontáneo, libre y autónomo, del que habla Cuenca (2009), con el consumo excesivo de lo que parece gustarle al ser humano trabajador, que hace uso del tiempo libre controlado que le permite la industria, porque lo utiliza en consumir entretenimiento creado por esta misma. La educación del ocio no existe, existe la educación para el trabajo y el consumo.

Bien lo describe Rul-lán (1997) cuando habla de la llegada del protestantismo con Calvino -con lo que se podría retomar el factor de la religión mencionado en un pasaje anterior-, quien asegura que el número de elegidos por Dios, para salvarse,

[...] ya estaba determinado desde la eternidad. [...] el éxito en los negocios, se convirtió en signo seguro de predestinación. Dios bendice a los suyos dándoles éxito en su trabajo. Por tanto, cuanto más trabajas, más rico te hacías, y cuanto más rico te hacías más clara era la señal de que Dios te amaba y te había elegido. [...] Con el calvinismo se dio la vuelta completa y lo que antes era casi despreciado, el negocio, se convirtió en el máximo valor moral, mientras que lo que era exaltado antiguamente, el ocio, se convirtió en el gran pecado (p. 181).

Definitivamente estamos educándonos para el trabajo, no para el ocio o ser felices dice Rul-lan (1997):

En este nuestro mundo de mercaderes, lo importante en la educación formal de la escuela y la universidad, o la informal de la familia y la sociedad, es enseñar a negar el ocio, a hacer negocio, produciendo, comprando y vendiendo. Pero, ¿de qué servirán a nuestros jóvenes "tantas idas y venidas, tantas vueltas y revueltas" en el negocio, si al final todos sus esfuerzos terminan en una terrible quiebra de lo único que importa que es la felicidad? (p. 172).
Colombia es uno de los países que conserva esta idea renacentista de la predestinación, de que el cielo es para ricos, de que el éxito lo tiene aquel con el mejor auto, mejores vestidos y mejor empleo, lo que implica tener más que el otro. "En Colombia se tiene la idea de que el empleado que trabaja los siete días de la semana y hasta que lleva trabajo para su casa, es el mejor" (Caicedo, 2011). Esto forma parte del círculo vicioso del consumismo que impide hacer uso de las bondades de la contemplación de las que hablaban los filósofos de la Grecia clásica y que permitiría observar al mundo más allá de la remuneración, que luego será gastada en objetos y servicios vendidos por los mismos dueños de las fábricas y empresas para quienes trabajamos la mayor parte de nuestras vidas. ¿A quién más si no a ellos les interesa vender esa idea renacentista?

A este punto, la pretensión de la que hablan Duque, Franco y Escobar (2008) se acoge prácticamente en su totalidad a la orientación de este escrito cuando incentivan a

[...] abolir el trabajo obligante a tiempo completo y extenuante para facilitar las posibilidades de ocio; pero no un ocio que envilezca al humano [...] [sino uno que] le aporta a la liberación del Ser de la alineación a la que conllevan las prácticas homogeneizantes de los sistemas del mercado capitalista, pero no desconoce al trabajo como otro frente del desarrollo o florecimiento humano.

[...] el ejercicio de las prácticas de ocio preferidas y elegidas crítica, reflexiva y libremente propician el florecimiento humano (pp. 199, 200).

Con esta recopilación se buscó generar el interés de reflexionar acerca de la influencia del sistema educativo colombiano en la formación y percepción del trabajo, y cómo esto interfiere también con el reconocimiento que los trabajadores tienen acerca del tiempo de ocio. 


\section{REFERENCIAS BIBLIOGRÁFICAS}

Archila, M. (2010). Cultura e identidad obrera, Colombia 1910-1945. Bogotá: Cinep.

Bermúdez, M. (2011). Algunas reflexiones sobre el currículo en la educación. Contribuciones a las Ciencias Sociales. Recuperado de: http://www.eumed.net/rev/ cccss $/ 16 / \mathrm{mba} . \mathrm{html} \#$

Caicedo, C. (2011). El trabajo flexible se impone a nivel mundial, pero en Colombia tiene sus detractores. Actualícese.com. Recuperado de: http://actualicese. com/actualidad/2011/03/24/el-trabajo-flexible-seimpone-a-nivel-mundial-pero-en-colombia-tiene-susretractores/\#

Caicedo, E. (1974). Historia de las luchas sindicales en Colombia. Bogotá: Suramérica Ltda.

Capella, L. (2 de septiembre de 1910). El clero es responsable de las guerras civiles. El Símbolo, p.p. 1-2. Recuperado de: http://www.bibliotecanacional. gov.co/recursos_user/expv/pobrera/elsimbolo_8_ cartagena_1910.pdf

Corominas, J. (1987). Diccionario etimológico de la lengua castellana. Madrid: Gredos.

Departamento Administrativo Nacional de Estadística (DANE) (2012). Fuerza laboral y educación. Recuperado de: http://www.dane.gov.co/files/investigaciones/ boletines/especiales/educacion/Bol_edu_2011.pdf

Duque, H.; Franco, S. y Escobar, A. (2008). Fundamentos conceptuales del ocio crítico desde una perspectiva latinoamericana. Tesis para optar al título de Magíster en Motricidad-Desarrollo Humano. Medellín: Universidad de Antioquia.

Elizalde, R. y Gomes, C. (2010). Ocio y recreación en América Latina: conceptos, abordajes y posibilidades de resignificación. Polis 9(26), 1-16.

Gawriszewski, B. (2003). La lucha capitalista contra el ocio: la necesidad de un ocio consumista. Educación Física y Deportes, 66. Recuperado de: http://sociologiatl. wordpress.com/2011/03/17/la-lucha-capitalistacontra-el-ocio-la-necesidad-de-un-ocio-consumista/

Hernández, D. (2012). La escuela de ocio: tiempo libre y filosofía antigua. Cuadernos Hispanoamericanos, 747, 77-99. Recuperado de: https://www.academia. edu/2927349/La_escuela_del_ocio_Tiempo_libre_y_ filosofia_antigua._In_Cuadernos_hispanoamericanos_ ISSN_0011-250X_747_2012_77-100

Miranda, G. (2006). El tiempo libre y ocio reivindicado por los trabajadores. Pasos 4(3), 301-326.

Otero, J. (2009). La pedagogía del ocio: nuevos desafíos. Lugo, España: AXAC.

Rul-lán, G. (1997). Del ocio al negocio... y otra vez al ocio. Papers, 53, 171-193.

Russell, B. (1932). Elogio a la ociosidad. Recuperado de: http://www.alcoberro.info/pdf/russell3.pdf

Tabares, F. (2005). El ocio, el tiempo libre y la recreación en América Latina: problematizaciones y desafíos. Medellín: Civitas.

Tabares, F. (2010). Juegos populares y tradicionales, ocio y diferencia colonial. [En línea]. Polis, 26. Recuperado de: http://polis.revues.org/187. DOI : 10.4000/polis.187 2010.

Taylor, J. (2010). Historia secreta del sistema educativo. Recuperado de: http://historiasecretadelsistema educativo.weebly.com/indicegeneral.html

Uribe, J. (2006). Evolución de la educación en Colombia durante el siglo xx. Revista del Banco de la República LXXIX(940), 1-16. 